\title{
Increases of correct memories and spontaneous false memories due to eye movements when memories are retrieved after a time delay
}

Citation for published version (APA):

Houben, S. T. L., Otgaar, H., Roelofs, J., Smeets, T., \& Merckelbach, H. (2020). Increases of correct memories and spontaneous false memories due to eye movements when memories are retrieved after a time delay. Behaviour Research and Therapy, 125, [103546]. https://doi.org/10.1016/j.brat.2019.103546

Document status and date:

Published: 01/02/2020

DOI:

10.1016/j.brat.2019.103546

Document Version:

Publisher's PDF, also known as Version of record

\section{Document license:}

Taverne

Please check the document version of this publication:

- A submitted manuscript is the version of the article upon submission and before peer-review. There can be important differences between the submitted version and the official published version of record.

People interested in the research are advised to contact the author for the final version of the publication, or visit the DOI to the publisher's website.

- The final author version and the galley proof are versions of the publication after peer review.

- The final published version features the final layout of the paper including the volume, issue and page numbers.

Link to publication

\footnotetext{
General rights rights.

- You may freely distribute the URL identifying the publication in the public portal. please follow below link for the End User Agreement:

www.umlib.nl/taverne-license

Take down policy

If you believe that this document breaches copyright please contact us at:

repository@maastrichtuniversity.nl

providing details and we will investigate your claim.
}

Copyright and moral rights for the publications made accessible in the public portal are retained by the authors and/or other copyright owners and it is a condition of accessing publications that users recognise and abide by the legal requirements associated with these

- Users may download and print one copy of any publication from the public portal for the purpose of private study or research.

- You may not further distribute the material or use it for any profit-making activity or commercial gain

If the publication is distributed under the terms of Article 25fa of the Dutch Copyright Act, indicated by the "Taverne" license above, 


\title{
Increases of correct memories and spontaneous false memories due to eye movements when memories are retrieved after a time delay
}

\author{
Sanne T.L. Houben ${ }^{\mathrm{a}, \mathrm{b}, *}$, Henry Otgaar ${ }^{\mathrm{a}, \mathrm{b}}$, Jeffrey Roelofs ${ }^{\mathrm{a}}$, Tom Smeets ${ }^{\mathrm{c}}$, Harald Merckelbach ${ }^{\mathrm{a}}$ \\ ${ }^{\text {a }}$ Clinical Psychological Science, Maastricht University, the Netherlands \\ ${ }^{\mathrm{b}}$ Leuven Institute of Criminology, Catholic University of Leuven, Belgium \\ ${ }^{\mathrm{c}}$ CoRPS - Center of Research on Psychological and Somatic Disorders, Department of Medical and Clinical Psychology, Tilburg University, the Netherlands
}

\section{A R T I C L E I N F O}

\section{Keywords:}

Eye movements

EMDR

False memory

DRM

Therapy

\begin{abstract}
A B S T R A C T
Eye Movement Desensitization and Reprocessing (EMDR) is an effective treatment for post-traumatic stress disorder. However, literature on possible adverse memory effects of EMDR is scarce. Using the Deese/RoedigerMcDermott (DRM) false memory paradigm, we examined the susceptibility to spontaneous false memories after performing eye movements, as used in EMDR. In Experiment 1, 72 undergraduates received word lists containing negative and neutral associated words and immediately after this they were given a free recall and recognition test. In Experiment 2, 68 undergraduates underwent the free recall and recognition test $48 \mathrm{~h}$ later. During the free recall phase in both experiments, participants either performed eye movements or not (control condition). In Experiment 1, the two conditions did not differ statistically with regard to correct and false recall/ recognition. In Experiment 2, correct memory rates were higher in the eye movement than in the control condition and this was accompanied by an increase in spontaneous false memories on both free recall and recognition. Although our experimental approach is far removed from clinical practice, our findings suggest that eye movements as used in EMDR might amplify both correct and false memory rates.
\end{abstract}

Eye Movement Desensitization and Reprocessing (EMDR; Shapiro, 1989 ) is a widely used treatment for trauma-related disorders (de Jongh \& ten Broeke, 2016). During EMDR, patients retrieve traumatic memories and are instructed to concentrate on the core cognitions they have about themselves as well as on the emotions, thoughts, and bodily sensations that emerge (Shapiro \& Maxfield, 2002). Simultaneously, the therapist induces eye movements by moving the index finger horizontally in front of the patient's visual field or by using an electronic device such as the EMDR kit (see https://www.emdrkit.com). Typically, eye movements lead to a reduction in self-reported vividness and emotionality of the traumatic memory (e.g., van den Hout \& Engelhard, 2012).

Laboratory studies generally support the beneficial effects (i.e., reductions in vividness and emotionality) of eye movements. In these studies, healthy participants are asked to retrieve a negative autobiographical memory and rate its vividness and emotionality on a visual analogue scale (VAS). Following this, participants perform horizontal eye movements (i.e., tracking a moving dot on a computer screen) for several episodes of $24 s$ or not (i.e., control condition; van den Hout \& Engelhard, 2012), and rate the vividness and emotionality of their memory on a VAS once more. In general, eye movements decrease participants' memory vividness and emotionality (Lee \& Cuijpers, 2013).

According to the working memory account, the therapeutic power of eye movements is due to their interference with working memory (Gunter \& Bodner, 2008; van den Hout \& Engelhard, 2012). This account stipulates that performing eye movements and retrieving an autobiographical memory both require working memory capacity. As working memory capacity is limited (Baddeley, 1998), less capacity is available for memory retrieval when it is accompanied by eye movements. This trade-off between memory and eye movements will manifest itself in reduced vividness and emotionality of the traumatic memory, a phenomenon called imagination deflation (van den Hout \& Engelhard, 2012).

\section{Eye movements and false memory production}

Using a fear condition procedure, Leer et al. (2017; Experiment 2) showed that eye movements, as used in EMDR, decrease memory accuracy. Research on adverse therapy effects has great practical relevance (e.g., Moritz et al., 2015) and with this in mind, researchers became interested in whether EMDR, specifically eye movements,

\footnotetext{
* Corresponding author. Maastricht University, Clinical Psychological Science, Universiteitssingel 40, 6229 ER, Maastricht, the Netherlands.

E-mail address: sanne.houben@maastrichtuniversity.nl (S.T.L. Houben).
} 
might increase individual's susceptibility to false memories (i.e., memories of non-experienced details or events; Loftus, 2004). One distinct possibility is that eye movements, through its taxing of working memory, make participants more susceptible to incorporate misinformation into their memory report. Houben, Otgaar, Roelofs, and Merckelbach (2018) found suggestive evidence for such an effect. In their experiment, participants saw a car crash video, then performed eye movements or not, and finally were exposed to misinformation about the video. Eye movements increased endorsement of misinformation. However, it remains to be seen whether the false memory creating potential of eye movements is a robust phenomenon. Importantly, two recent direct replications (Calvillo \& Emami, 2019; van Schie \& Leer, 2019) failed to reproduce the phenomenon. Clearly, these contradictory findings require follow-up research. In this previous work on false memory and eye movements, researchers attempted to elicit false memories by providing participants with misinformation. So far, few studies examined whether eye movements might amplify false memories that arise spontaneously (i.e., without any external pressure). van Schie \& Leer, 2019 also noted this omission and recommended to use methods that rely on automatic memory dynamics, rather than external pressure.

One of the most popular and reliable methods to elicit spontaneous false memories is the Deese-Roediger-McDermott (DRM; Deese, 1959; Roediger \& McDermott, 1995) paradigm. In this paradigm, participants receive wordlists containing associated words (e.g., bed, tired, dream, etc.) that are all linked to a non-presented word, termed the critical lure (i.e., sleep). Free recall and recognition tests have demonstrated that many participants falsely remember the critical lure (e.g., Gallo, 2010).

Knott and Dewhurst (2007b; Experiment 2) had participants study DRM wordlists under full attention and carried out a recognition test in full or divided attention (i.e., generate number during recognition). Divided attention at retrieval led to lower correct recognition rates, and, more interestingly, increased false recognition rates. Shah and Knott (2018) replicated this and found that divided attention at retrieval (i.e., generating numbers during retrieval) led to higher rates of both negative and neutral false memories. The authors also measured metacognitive remember/know responses to examine whether false reports were accompanied by vivid, conscious recollections (i.e., remember response) and/or a strong sense of familiarity (i.e., know response). It appeared that divided attention increased recollection but not familiarity aspect of both negative and neutral false memories (Shah \& Knott, 2018).

So far, only few authors employed the DRM paradigm to systematically examine the link between eye movements and spontaneous false recognition. In the studies of Parker and Dagnall (2007; 2012), participants heard the associated words and were randomly assigned to either a horizontal, vertical, or no eye movement condition. Participants' memory was tested with a recognition task. Horizontal eye movements resulted in higher hit rates and reduced false recognition rates (i.e., false memories) compared with vertical eye movements and no eye movements condition (see also Christman, Propper, \& Dion, 2004; Nieuwenhuis et al., 2013).

However, previous work on eye movements and false memories elicited by a DRM paradigm suffers from two important limitations. First, during real life EMDR sessions, patients retrieve their memory while simultaneously performing eye movements. However, in the laboratory studies of Parker and Dagnall (2007; 2012), eye movements were carried out after they received the associated words. A second limitation is that their studies involved neutral (false) memory material, whereas EMDR is typically applied to traumatic memories.

\section{The current study}

The aim of the current study was to examine whether eye movements, as used in EMDR, may amplify spontaneous false memory susceptibility. In contrast to previous studies (e.g., Parker \& Dagnall, 2007), participants had to perform eye movements during the retrieval of memories. Furthermore, participants were presented with neutral and emotionally negative DRM lists.

The reason for using emotionally negative and neutral word lists was twofold. First, as said before, EMDR is usually applied to emotionally negative memories. Second, research on the effects of valence on false memory formation has consistently shown that negative valence affects false memory rates (for an overview see Bookbinder \& Brainerd, 2016). Specifically, during free recall, false memory rates are higher for neutral than for negative stimuli, whereas the reverse occurs during recognition. We anticipated to find a similar pattern of findings.

Based on previous findings on divided attention and false memory generation (Shah \& Knott, 2018), we expected that participants in the eye movement condition would be more susceptible to false memory creations as compared to control participants (on free recall and recognition test). Our reasoning was that eye movements would engender divided attention, leading participants to focus on the gist rather than the details of the retrieved memories. Such enhancement of gist memory would make participants more prone to false memory production (Brainerd \& Reyna, 2002). In the current study, we also measured remember/know responses. We predicted that eye movements would lead to fewer remember and know responses for correct memories than when no eye movements were performed (Knott \& Dewhurst, 2007a). For critical lures, we expected to find that eye movements would lead to more remember responses than know responses.

In clinical practice, there is often a considerable time interval between encoding of the traumatic event and receiving treatment, such as EMDR. To approach this situation more closely (i.e., encoding an event and retrieving the corresponding memory days later), free recall and recognition test were administered in Experiment 2 after a delay of $48 \mathrm{~h}$. We expected higher false memory levels in Experiment 2 than in Experiment 1. Our expectation is derived from Fuzzy Trace Theory (FTT; Brainerd \& Reyna, 2002), which stipulates that it will become more difficult to retrieve verbatim traces when time passes and individuals have to rely on gist traces. The increased reliance on gist traces will likely stimulate false memory production.

\section{Experiment 1}

\subsection{Method}

\subsubsection{Participants}

The experiments were preregistered at the Open Science Framework (see https://osf.io/gx7te/registrations/). The preregistration included a 2 (Condition: Eye Movement vs. Control) $\times 2$ (Valence: Neutral vs. Negative) $\times 2$ (Time: Immediate vs. Delayed) mixed design and power analysis. Based on previous research (Parker \& Dagnall, 2012; study on eye movements and false memories with an effect size of $\eta_{\text {partial }}^{2}=0.04$ ), an a priori power analysis using $\mathrm{G}^{*}$ Power (Faul, Erdfelder, Lang, \& Buchner, 2007), with a medium effect size $(f=0.25$; Howe, Wimmer, Gagnon, \& Plumpton, 2009) and a power of 0.80, showed that a total sample size of 136 participants was needed. As participants were not randomly assigned for the variable Time (see below), two separate experiments are reported (Experiment $1 n=72$, Experiment $2 n=68$ ).

The sample of Experiment 1 consisted of 16 psychology and 56 medicine undergraduate students of Maastricht University $(N=72$, $M_{\text {age }}=21.07, S D=2.27$, range $18-30,66$ women; $n=36$ per condition). Participants were asked whether they had prior knowledge of what EMDR entails. Five participants of the experimental condition indicated to have knowledge of EMDR, but these participants were not excluded as previous research showed that prior knowledge does not affect any memory effects of EMDR (Littel, van 
Schie, \& van den Hout, 2017). ${ }^{1}$ All participants provided written consent and received course credits or a financial reimbursement of $€ 7,50$ for their participation. All participants were native Dutch speakers. The experiment was approved by the standing ethical committee of the Faculty of Psychology and Neuroscience.

\subsubsection{Materials}

All data and materials are available at the Open Science Framework at https://osf.io/gx7te/.

Deese/Roediger-McDermott (DRM) Paradigm. Five neutral DRM lists (critical lures: bread, window, sweet, smoke, foot) and five negative DRM lists (critical lures: murder, pain, punishment, death, cry) were used as stimulus material. These Dutch DRM wordlists (https://osf.io/n2fve/ ) are known to reliably induce false memories (see e.g., Otgaar, Peters, \& Howe, 2012). Each DRM list included ten associated words. The order of word lists presentation was counterbalanced (i.e., neutral DRM lists negative DRM lists; negative DRM lists - neutral DRM lists). Mean word frequency of neutral and negative critical lures did not differ statistically $(t(8)=0.22, n s)$.

Eye Movement Task. To simulate the eye movement component of EMDR in a standardized way, an EMDR kit version 2.0 was used (see https://www.emdrkit.com/). This kit is also employed for therapeutic purposes. A white dot was presented on a bar (length light bar $70 \mathrm{~cm}$ ) and moved from left to right with one movement per second (speed: $12 / 15$; one movement per second), during four episodes of $24 s$ with a $10 s$ interval. The duration was in line with previous research (van den Hout \& Engelhard, 2012) and largely converges to general procedures in EMDR therapy. All participants sat at a $30 \mathrm{~cm}$ distance from the EMDR kit. The researcher checked whether participants complied with the eye movement instructions by monitoring the participants' eye movements. Control participants viewed a blank screen on a computer.

Free Recall. During the four episodes of performing eye movements (or not), participants were asked to freely recall the words they could remember at this point in time (see for details below). The free recall was audiotaped. Free recall was scored in a liberal manner. That is, if the presented word was "shoes" and the participant recalled the word "shoe" this was scored as a correct response (i.e., from plural to singular or vice versa). If we would have scored in a conservative manner (i.e., exact reproduction), the word "shoe" would have been treated as an incorrect response. Repetition of the same word was not included in total words recalled.

Recognition Test. The recognition test (https://osf.io/5desv/) for the DRM lists contained of 78 words including 40 correct items (e.g., flour, blood), ten critical lures (e.g., bread, murder), ten non-presented related items (e.g., syrup, shooting), and 18 non-presented unrelated items (e.g., bus, friend). The recognition test was administered orally. Additionally, whenever participants indicated to recognize a word, they were asked to make a remember/know response. It was explained to participants that the remember option referred to vivid, clear recollections and the know option to memories accompanied by a strong sense of familiarity (Tulving, 1985).

Dissociative Experiences Scale. The Dissociative Experiences Scale (DES; Bernstein \& Putnam, 1986; https://osf.io/h3xs6/) was included for explorative analyses. It measures self-reported dissociative tendencies in, for example, memory (e.g., not remembering whether you have actually done something, or only thought about it). The DES contains 28 items that ask participants to rate the frequency of these experiences. In the current experiment, participants used a $100-\mathrm{mm}$ scale to indicate the percentage of time they experienced such dissociative phenomena $(0=$ not at all; $100=$ very much). Higher DES scores indicate a higher frequency of self-reported dissociative experiences. The internal consistency of the DES in the current study was

\footnotetext{
${ }^{1}$ Excluding participants who had knowledge about EMDR did not influence the results. Therefore, we included these participants in the final dataset.
}

good (Cronbach's $\alpha=0.90$ ). Results of the DES can be found on the OSF (https://osf.io/5x6qt/).

\subsubsection{Design and procedure}

The experiment relied on a 2 (Condition: Eye movements vs. Control) $\times 2$ (Valence: Negative vs. Neutral) split-plot design. Condition was a between-subjects factor and Valence a within-subjects factor. The dependent variables were (a) correct recall and hit rates (i.e., correct responses during free recall and recognition, respectively), (b) false recall and false recognition (i.e., acceptance of critical lures during free recall and recognition, respectively), and (c) extra intrusions on free recall and recognition (i.e., reporting/acceptance of unpresented words). Additionally, we examined endorsement of remember and know responses.

Participants were randomly assigned to either the eye movement ( $n=36$ ) or the control condition $(n=36)$ and were tested individually in a quiet laboratory room. They were informed that they were about to take part in a word recognition study. After obtaining written informed consent, participants completed the DES. Then, they were instructed to pay close attention to the words presented on the computer screen. Participants were presented with five negative DRM lists and five neutral DRM lists, presented in a blocked order. Half of the participants first viewed the negative word lists, followed by the neutral word lists. The other half of the participants received the reversed order. The words appeared in the middle of the screen for $2 s$ (Knott \& Dewhurst, 2007a; Nieuwenhuis et al., 2013) followed by a blank screen for $2 s$. After each list, a '+' sign was shown. After viewing the DRM word lists, participants performed a filler task (playing the game Bejeweled) for $5 \mathrm{~min}$. This served as a distraction task and to ensure a delay between the stimuli and follow-up tasks. After $5 \mathrm{~min}$, the participants were told to stop and the free recall test began.

All participants received the instruction to recall words they could remember at this point in time, for four episodes of $24 \mathrm{~s}$ with a $10 \mathrm{~s}$ break between episodes. The experimenter stressed that it did not matter whether they recalled the words in a different order or repeated the same words. Participants were instructed to focus on their emotions, feelings, bodily sensations, and thoughts when recalling the words, similar to the EMDR protocol (de Jongh \& ten Broeke, 2016). Participants in the eye movement condition were additionally instructed to follow the dot with their eyes as it moved from left to right on the EMDR kit and were asked to keep their head still. The distance to the EMDR kit was $30 \mathrm{~cm}$. Compliance with these instructions was monitored by the experimenter. Participants in the control condition viewed a blank screen. Following the free recall phase, all participants completed a filler task for 5 min (playing Bejeweled). After this, they had to complete the recognition test. The experimenter recited words and participants were instructed to answer 'yes' if they recalled the word, or 'no' if they did not recall the word. If a 'yes' response was made, participants were asked to provide a remember or know response. Participants were debriefed after all participants were tested.

\section{Results}

Mean proportions of recall and recognition rates are shown in Table 1 . The various memory parameters were subjected to 2 (Condition: Eye Movements vs. Control) $\times 2$ (Valence: Negative vs. Neutral) repeated measures ANOVAs. Most effects, including the critical main effects of condition and interaction effects of condition with valence, did not reach statistically significant levels and had low Bayes Factors (BF; i.e., < 1.00; $\mathrm{BF}$ expresses the likelihood of the data under $\mathrm{H}_{1}$ relative to $\mathrm{H}_{0}$; JASP Team, 2019). Therefore, we do not elaborate on the main and interaction effects of all ANOVAs here. Instead, we refer to Table 2 for a summary of the data.

There were a few exceptions to this overall pattern. For false recall (i.e., critical lures), a 2 (Condition: Eye Movements vs. Control) $\times 2$ (Valence: Negative vs. Neutral) repeated measures ANOVA revealed a 
Table 1

Mean proportions and standard deviations per condition for recall and recognition of Experiment 1.

\begin{tabular}{llll}
\hline & & EM condition $(n=36)$ & Control condition $(n=36)$ \\
\hline Recall & & & \\
True recall & Negative & $0.26(.12)$ & $0.31(.14)$ \\
& Neutral & $0.29(.14)$ & $0.33(.15)$ \\
False recall & Negative & $0.21(.18)$ & $0.26(.24)$ \\
& Neutral & $0.29(.21)$ & $0.33(.23)$ \\
Recognition & & & \\
Hit rate & Negative & $0.78(.14)$ & $0.86(.11)$ \\
& Neutral & $0.79(.13)$ & $0.80(.14)$ \\
Critical lures & Negative & $0.74(.24)$ & $0.72(.28)$ \\
& Neutral & $0.73(.23)$ & $0.65(.25)$ \\
\hline
\end{tabular}

Note. $\mathrm{EM}=$ Eye movement.

statistically significant main effect of valence. Overall, participants falsely recalled more neutral lures $(M=0.31, S D=0.14)$ than negative lures $\left(M=0.28, S D=0.13 ; F(1,70)=5.11, p=.027, \eta_{\text {partial }}^{2}=.068\right.$, $\mathrm{BF}_{10}=2.24$ ). A 2 (Condition: Eye Movements vs. Control) $\times 2$ (Valence: Negative vs. Neutral) repeated measures ANOVA performed on the know responses related to hits yielded a statistically significant main effect of valence. Participants provided more know responses for negative hits $(M=0.16, S D=0.12)$ than for neutral hits $(M=0.10$, $S D=0.10 ; F(1,70)=21.91, p<.001, \eta_{\text {partial }}^{2}=.238$, $\mathrm{BF}_{10}=1752.86$ ). A 2 (Condition: Eye Movements vs. Control) $\times 2$ (Valence: Negative vs. Neutral) repeated measures ANOVA performed on the know responses related to false recognition yielded a statistically significant main effect of valence. That is, participants provided more know responses for negative critical lures $(M=0.27, S D=0.23)$ than for neutral critical lures $(M=0.19, S D=0.19 ; F(1,70)=5.66$, $\left.p=.020, \eta_{\text {partial }}^{2}=.075, \mathrm{BF}_{10}=2.60\right)$.

\section{Discussion}

In Experiment 1, eye movements did not increase the susceptibility to spontaneous false memory formation. In line with previous studies, participants falsely recalled more neutral lures than negative lures (Pesta, Murphy, \& Sanders, 2001). We also found that know responses more often accompanied hits and false recognition of negative material than hits and false recognition of neutral material.

To approach the therapeutic situation more closely (i.e., encoding an event and retrieving the corresponding memory days later), we conducted Experiment 2 that deviated from Experiment 1 in that here we used a longer time window (i.e., $48 \mathrm{~h}$ ) between memory encoding and eye movement manipulations.

\section{Experiment 2}

\subsection{Participants}

The preregistration included a 2 (Condition: Eye Movement vs. Control) $\times 2$ (Valence: Neutral vs. Negative) $\times 2$ (Time: Immediate vs. Delayed) mixed design and power analysis. Based on previous research (Parker \& Dagnall, 2012; study on eye movements and false memories with an effect size of $\eta_{\text {partial }}^{2}=0.04$ ), an a priori power analysis using G*Power (Faul et al., 2007), with a medium effect size ( $f=0.25$; Howe et al., 2009) and a power of 0.80 , showed that a total sample size of 136 participants was needed. As said before, participants were not randomly assigned for the variable Time, and so two separate experiments are reported (Experiment $1 n=72$, Experiment $2 n=68$ ). In the Experiment 2, the sample included 21 psychology and 47 medicine undergraduate students of Maastricht University $\left(N=68, M_{\text {age }}=20.51\right.$,

Table 2

Results Statistical Analyses of Experiment 1.

\begin{tabular}{|c|c|c|c|c|c|}
\hline & & $\mathrm{F}$ & $\mathrm{p}$ & Partial eta ${ }^{2}$ & $\mathrm{BF}_{10}$ \\
\hline \multicolumn{6}{|l|}{ Free Recall } \\
\hline \multirow[t]{3}{*}{ True recall } & Main effect condition & 3.42 & 0.069 & 0.047 & 0.74 \\
\hline & Main effect valence & 1.62 & 0.207 & 0.023 & 0.41 \\
\hline & Interaction effect condition $\times$ valence & 0.08 & 0.781 & 0.001 & 0.08 \\
\hline \multirow[t]{3}{*}{ False recall } & Main effect condition & 1.20 & 0.278 & 0.017 & 0.34 \\
\hline & Main effect valence & 5.11 & 0.027 & 0.068 & 2.24 \\
\hline & Interaction effect condition $\times$ valence & 0.06 & 0.802 & 0.001 & 0.09 \\
\hline \multicolumn{6}{|l|}{ Recognition } \\
\hline \multirow[t]{3}{*}{ Hit rates } & Main effect condition & 2.98 & 0.089 & 0.041 & 0.81 \\
\hline & Main effect valence & 1.83 & 0.180 & 0.025 & 0.42 \\
\hline & Interaction effect condition $\times$ valence & 3.26 & 0.075 & 0.044 & 0.34 \\
\hline \multirow[t]{3}{*}{ False recognition } & Main effect condition & 0.96 & 0.331 & 0.014 & 0.41 \\
\hline & Main effect valence & 1.68 & 0.199 & 0.023 & 0.38 \\
\hline & Interaction effect condition $\times$ valence & 1.24 & 0.270 & 0.017 & 0.07 \\
\hline \multirow[t]{3}{*}{$\mathrm{R}$ response for hits } & Main effect condition & 2.42 & 0.125 & 0.033 & 0.65 \\
\hline & Main effect valence & 2.47 & 0.121 & 0.034 & 0.59 \\
\hline & Interaction effect condition $\times$ valence & 0.87 & 0.354 & 0.012 & 0.12 \\
\hline \multirow[t]{3}{*}{$\mathrm{R}$ response for CL } & Main effect condition & 0.06 & 0.810 & 0.000 & 0.27 \\
\hline & Main effect valence & 0.15 & 0.700 & 0.002 & 0.19 \\
\hline & Interaction effect condition $\times$ valence & 0.29 & 0.589 & 0.004 & 0.01 \\
\hline \multirow[t]{3}{*}{$\mathrm{K}$ response for hits } & Main effect condition & 0.18 & 0.671 & 0.003 & 0.26 \\
\hline & Main effect valence & 21.91 & $<.001$ & 0.238 & 1752.86 \\
\hline & Interaction effect condition $\times$ valence & 0.20 & 0.659 & 0.003 & 0.08 \\
\hline \multirow[t]{3}{*}{$\mathrm{K}$ response for $\mathrm{CL}$} & Main effect condition & 1.65 & 0.203 & 0.23 & 0.44 \\
\hline & Main effect valence & 5.66 & 0.020 & 0.75 & 2.60 \\
\hline & Interaction effect condition $\times$ valence & 0.30 & 0.585 & 0.004 & 0.13 \\
\hline Intrusions & & $t$ & $p$ & $95 \% \mathrm{CI}$ & \\
\hline Free recall & & 1.79 & 0.077 & {$[-.07,1.41]$} & 0.96 \\
\hline \multirow[t]{2}{*}{ Recognition } & Related & 0.82 & 0.418 & {$[-.36, .86]$} & 0.32 \\
\hline & Unrelated & -0.68 & 0.496 & {$[-.07, .03]$} & 0.28 \\
\hline
\end{tabular}

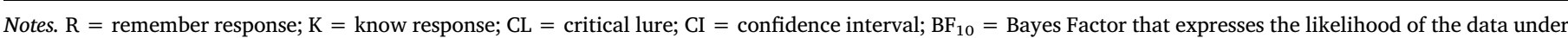
$\mathrm{H}_{1}$ relative to $\mathrm{H}_{0}$. 
$S D=2.00$, range $18-26,59$ women; $n=34$ per condition). Five participants indicated to have knowledge about EMDR, but they were not excluded. ${ }^{2}$

All participants provided written consent and received course credits or a financial reimbursement of $€ 7,50$ for their participation. All participants were native Dutch speakers. Participants in Experiment 2 did not participate in Experiment 1. The experiment was approved by the standing ethical committee for the Faculty of Psychology and Neuroscience.

\subsection{Materials}

Materials were the same as in Experiment 1 and the data and materials can be found at the Open Science Framework https://osf.io/ gx7te/.

\subsection{Design and procedure}

The design and procedure of Experiment 2 were similar to Experiment 1, except for the following changes. The procedure involved two sessions with a $48 \mathrm{~h}$ interval in between. During session one, participants completed the DES and viewed the DRM word lists. During session 2 ( $48 \mathrm{~h}$ later), participants were randomly assigned to either the eye movement $(n=34)$ or control condition $(n=34)$ and completed the free recall and recognition test and received the same instructions as in Experiment 1. Participants were debriefed after all participants were tested.

\section{Results}

Mean proportions of recall and recognition rates are shown in Table 3. The results are summarized in Table 4.

\subsection{Free Recall}

True Recall. A 2 (Condition: Eye Movements vs. Control) $\times 2$ (Valence: Negative vs. Neutral) repeated measures ANOVA was performed on correct recall. A statistically significant interaction effect emerged, $F(1,66)=6.80, p=.011, \eta^{2}$ partial $=.093, \mathrm{BF}_{10}=5.06$. Simple effect analysis revealed that participants in the eye movement condition recalled more neutral items $(M=0.23, S D=0.17)$ than control participants $(M=0.12, S D=0.13), F(1,66)=9.80, p=.003$, $\left.\eta_{\text {partial }}^{2}=.129\right)$. No statistical difference was found for negative items $(F$ $\left.(1,66)=0.14, p=.71, \eta_{\text {partial }}^{2}=.002\right)$.

False Recall. A 2 (Condition: Eye Movements vs. Control) $\times 2$ (Valence: Negative vs. Neutral) repeated measures ANOVA yielded a non-significant interaction, $F(1,66)=0.58, p=.45, \eta_{\text {partial }}^{2}=.009$. A statistically significant main effect of condition emerged, $F$ $(1,66)=4.43, p=.039, \eta_{\text {partial }}^{2}=.063, \mathrm{BF}_{10}=1.19$. That is, participants in the eye movement condition $(M=0.27, S D=0.17)$ falsely recalled more critical lures than control participants $(M=0.19$, $S D=0.14)$. No main effect of valence was found, $F(1,66)=0.06$, $p=.80, \eta_{\text {partial }}^{2}=.001$.

Intrusions. An independent samples $t$-test on the number of intrusions yielded no statistical difference between the groups $(t(66)=0.48$, $p=.63,95 \%$ CI $[-1.12,1.83])$.

\subsection{Recognition}

Hit Rates. A 2 (Condition: Eye Movements vs. Control) $\times 2$ (Valence: Negative vs. Neutral) repeated measures ANOVA yielded

\footnotetext{
${ }^{2}$ As was the case in Experiment 1, excluding participants who had knowledge about EMDR did not influence the results and therefore they were included in the final dataset.
}

Table 3

Mean proportions and standard deviations per condition for recall and recognition of Experiment 2.

\begin{tabular}{llll}
\hline & & EM condition $(n=34)$ & Control condition $(n=34)$ \\
\hline Recall & & & \\
True recall & Negative & $0.15(.12)$ & $0.14(.10)$ \\
& Neutral & $0.23(.17)$ & $0.12(.13)$ \\
False recall & Negative & $0.25(.22)$ & $0.20(.17)$ \\
& Neutral & $0.29(.21)$ & $0.18(.24)$ \\
Recognition & & & \\
Hit rate & Negative & $0.73(.11)$ & $0.68(.20)$ \\
& Neutral & $0.65(.21)$ & $0.59(.19)$ \\
Critical lures & Negative & $0.82(.20)$ & $0.72(.28)$ \\
& Neutral & $0.73(.29)$ & $0.55(.27)$ \\
\hline
\end{tabular}

Note. $\mathrm{EM}=$ Eye movement.

neither a statistically significant interaction effect, $F(1,66)=0.08$, $p=.78, \eta_{\text {partial }}^{2}=.001$, nor a main effect for condition, $F(1,66)=2.33$, $p=.13, \eta_{\text {partial }}^{2}=.034$. A main effect of valence emerged, $F$ $(1,66)=9.61, p=.003, \eta_{\text {partial }}^{2}=.127, \mathrm{BF}_{10}=14.48$, such that more negative words $(M=0.70, S D=0.16)$ than neutral words $(M=0.62$, $S D=0.20)$ were recognized.

False Recognition. A 2 (Condition: Eye Movements vs. Control) $\times 2$ (Valence: Negative vs. Neutral) repeated measures ANOVA found no statistically significant interaction effect, $F$ $(1,66)=1.20, p=.28, \eta_{\text {partial }}^{2}=.018$. The main effect of condition was statistically significant, $F(1,66)=6.88, p=.011, \eta_{\text {partial }}^{2}=.094$, $\mathrm{BF}_{10}=3.84$. More specifically, participants in the eye movement condition falsely recognized more critical lures $(M=0.77, S D=0.21)$ than control participants $(M=0.64, S D=0.22)$. A main effect of valence was also found, $F(1,66)=11.84, p=.001, \eta_{\text {partial }}^{2}=.152$, $\mathrm{BF}_{10}=31.42$, in that more negative $(M=0.77, S D=0.25)$ than neutral critical lures were recognized $(M=0.64, S D=0.29)$.

Intrusions. An independent samples $t$-test was performed on false alarms for related and unrelated non-presented items. Participants in the eye movement condition $(M=0.24, S D=0.12)$ reported statistically significant more related words than control participants $(M=0.18, S D=0.12 ; t(66)=-2.10, p=.040,95 \%$ CI $[-1.21$, $-0.30]$, Cohen's $\left.d=0.50, \mathrm{BF}_{10}=1.58\right)$. Also, participants in the eye movement condition $(M=0.23, S D=0.13$ ) recognized more unrelated words than control participants $(M=0.13, S D=0.09 ; t$ $(66)=-3.68, p<.001,95 \%$ CI $[-2.81,-0.83]$, Cohen's $d=0.89$, $\left.\mathrm{BF}_{10}=58.14\right)$.

\subsection{Remember/know}

Hit Rates. A 2 (Condition: Eye Movements vs. Control) $\times 2$ (Valence: Negative vs. Neutral) repeated measures ANOVA on endorsement of remember options yielded a statistically significant interaction effect, $F(1,66)=6.20, p=.015, \eta_{\text {partial }}^{2}=.086, \mathrm{BF}_{10}=3.33$. Simple effect analyses revealed a simple main effect of condition, but only for neutral hits. That is, participants in the eye movement condition $(M=0.49, S D=0.25)$ provided more remember responses than control participants $(M=0.37, S D=0.18)$ for neutral hits, $F$ $(1,66)=4.84, p=.031, \eta_{\text {partial }}^{2}=.068$, but not for negative hits $(F$ $\left.(1,66)=1.07, p=.30, \eta_{\text {partial }}^{2}=.016\right)$.

As for endorsement of know options, a 2 (Condition: Eye Movements vs. Control) $\times 2$ (Valence: Negative vs. Neutral) repeated measures ANOVA yielded a statistically significant interaction effect, $F$ $(1,66)=11.32, p=.001, \eta_{\text {partial }}^{2}=.146, \mathrm{BF}_{10}=17.02$. Simple effect analyses revealed a simple main effect of condition, but only for negative hits. That is, participants in the eye movement condition provided a know response to negative hits $(M=0.27, S D=0.12)$ more often than control participants $(M=0.20, S D=0.12 ; F(1.66)=5.94$, $\left.p=.018, \eta_{\text {partial }}^{2}=.083\right)$. 
Table 4

Results Statistical Analyses of Experiment 2.

\begin{tabular}{|c|c|c|c|c|c|}
\hline & & $\mathrm{F}$ & $\mathrm{p}$ & Partial eta ${ }^{2}$ & $\mathrm{BF}_{10}$ \\
\hline \multicolumn{6}{|l|}{ Free Recall } \\
\hline \multirow[t]{3}{*}{ True recall } & Main effect condition & 9.80 & 0.003 & 0.129 & 2.81 \\
\hline & Main effect valence & 0.14 & 0.71 & 0.002 & 0.33 \\
\hline & Interaction effect condition $\times$ valence & 6.80 & 0.011 & 0.093 & 5.06 \\
\hline \multirow[t]{3}{*}{ False recall } & Main effect condition & 4.43 & 0.039 & 0.063 & 1.19 \\
\hline & Main effect valence & 0.06 & 0.80 & 0.001 & 0.19 \\
\hline & Interaction effect condition $\times$ valence & 0.58 & 0.45 & 0.009 & 0.06 \\
\hline \multicolumn{6}{|l|}{ Recognition } \\
\hline \multirow[t]{3}{*}{ Hit rates } & Main effect condition & 2.33 & 0.13 & 0.034 & 0.62 \\
\hline & Main effect valence & 9.61 & 0.003 & 0.127 & 14.48 \\
\hline & Interaction effect condition $\times$ valence & 0.08 & 0.78 & 0.001 & 0.04 \\
\hline \multirow[t]{3}{*}{ False recognition } & Main effect condition & 6.88 & 0.011 & 0.094 & 3.84 \\
\hline & Main effect valence & 11.84 & 0.001 & 0.152 & 31.42 \\
\hline & Interaction effect condition $\times$ valence & 1.20 & 0.28 & 0.018 & 0.43 \\
\hline \multirow[t]{3}{*}{$\mathrm{R}$ response for hits } & Main effect condition & 4.84 & 0.031 & 0.068 & 0.33 \\
\hline & Main effect valence & 1.07 & 0.30 & 0.016 & 0.29 \\
\hline & Interaction effect condition $\times$ valence & 6.20 & 0.015 & 0.086 & 0.47 \\
\hline \multirow[t]{3}{*}{$\mathrm{R}$ response for $\mathrm{CL}$} & Main effect condition & 27.03 & $<.001$ & 0.291 & 6864.16 \\
\hline & Main effect valence & 1.00 & 0.32 & 0.015 & 0.29 \\
\hline & Interaction effect condition $\times$ valence & 0.00 & 1.00 & 0.000 & $4.06^{-5}$ \\
\hline \multirow[t]{3}{*}{$\mathrm{K}$ response for hits } & Main effect condition & 0.514 & 0.464 & 0.008 & 0.31 \\
\hline & Main effect valence & 6.246 & 0.015 & 0.086 & 2.16 \\
\hline & Interaction effect condition $\times$ valence & 11.32 & 0.001 & 0.146 & 17.02 \\
\hline \multirow[t]{3}{*}{$\mathrm{K}$ response for $\mathrm{CL}$} & Main effect condition & 11.23 & 0.001 & 0.145 & 11.84 \\
\hline & Main effect valence & 6.18 & 0.015 & 0.086 & 3.84 \\
\hline & Interaction effect condition $\times$ valence & 0.90 & 0.35 & 0.013 & 0.393 \\
\hline Intrusions & & $t$ & $p$ & $95 \% \mathrm{CI}$ & \\
\hline Free recall & & 0.48 & 0.63 & {$[-1.12,1.83]$} & 0.28 \\
\hline \multirow[t]{2}{*}{ Recognition } & Related & -2.10 & 0.040 & {$[-1.21,-0.30]$} & 1.58 \\
\hline & Unrelated & -3.68 & $<.001$ & {$[-2.81,-.83]$} & 58.14 \\
\hline
\end{tabular}

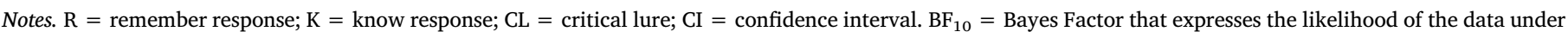
$\mathrm{H}_{1}$ relative to $\mathrm{H}_{0}$.

False Recognition. A 2 (Condition: Eye Movements vs. Control) $\times 2$ (Valence: Negative vs. Neutral) repeated measures ANOVA was performed for remember responses related to false recognition. No significant interaction effect was found, $F(1,66)=0.00$, $p=1.00, \eta_{\text {partial }}^{2}=.000$. However, a statistically significant main effect of condition was observed, $F(1,66)=27.03, p<.001, \eta_{\text {partial }}^{2}=.291$, $\mathrm{BF}_{10}=6864.16$. Participants in the eye movement condition provided more remember responses $(M=0.54, S D=0.24)$ than control participants $(M=0.27, S D=0.17)$. No main effect of valence emerged, $F$ $(1,66)=1.00, p=.32, \eta_{\text {partial }}^{2}=.015$.

A 2 (Condition: Eye Movements vs. Control) $\times 2$ (Valence: Negative vs. Neutral) repeated measures ANOVA performed on the know responses related to false recognition yielded no significant interaction effect between valence and condition, $F(1,66)=0.90, p=.35$, $\eta_{\text {partial }}^{2}=.013$. A statistically significant main effect of condition was found, $F(1,66)=11.23, p=.001, \eta_{\text {partial }}^{2}=.145, \mathrm{BF}_{10}=11.84$. More specifically, control participants provided more know responses to critical lures $(M=0.37, S D=0.18)$ than participants in the eye movement condition $(M=0.24, S D=0.16)$. A statistically significant main effect of valence was also found, $F(1,66)=6.18, p=.015$, $\eta_{\text {partial }}^{2}=.086, \mathrm{BF}_{10}=3.84$. More know responses for negative critical lures $(M=0.77, S D=0.25)$ than for neutral critical lures were observed $(M=0.64, S D=0.29)$.

An independent samples $t$-test was performed on the remember responses for related and unrelated words. For related words, participants in the eye movement condition $(M=0.09, S D=0.07)$ more often provided a remember response to related words than control participants $(M=0.03, S D=0.06 ; t(66)=-3.67, p<.001$, CI [-.91, $-0.27]$, Cohen's $\left.d=0.92, \mathrm{BF}_{10}=56.06\right)$. The same pattern was found for unrelated words. Participants in the eye movement condition $(M=0.06, S D=0.06)$ provided a remember response to unrelated words more often than control participants $(M=0.03, S D=0.04 ; t$
(66) $=-2.30, p=.024$, CI $[-.99, .07]$, Cohen's $d=0.59$, $\left.\mathrm{BF}_{10}=2.27\right)$.

An independent samples $t$-test performed on know responses for related words found no statistical difference between conditions $(t$ $(66)=-0.23, p=.820$ ). For unrelated words, a statistically significant difference emerged. Participants in the eye movement condition $(M=0.17, S D=0.10)$ provided a remember response to unrelated words more often than control participants $(M=0.10, S D=0.09 ; t$ (66) $=-3.00, p=.004$, CI $[-2.11,-0.42]$, Cohen's $d=0.73$, $\left.\mathrm{BF}_{10}=10.02\right)$.

\subsection{Exploratory Analyses}

Because participants in the eye movement condition frequently generated both more correct and false memories (i.e., critical lures) than did controls, we wondered whether their heightened false memory levels were an artefact of a positive response bias (Snodgrass \& Corwin, 1988). These analyses can be found on https://osf.io/89fyu/.

\section{Comparison between experiments}

In our preregistration, we were interested in the effect of time on spontaneous false memory formation. As said earlier, the preregistration included a 2 (Condition: Eye Movement vs. Control) $\times 2$ (Valence: Neutral vs. Negative) $\times 2$ (Time: Immediate Exp. 1 vs. Delayed Exp. 2) mixed design. Based on previous research (Parker \& Dagnall, 2012; study on eye movements and false memories with an effect size of $\eta_{\text {partial }}^{2}=0.04$ ), an a priori power analysis using $G^{*}$ Power (Faul et al., 2007), with a medium effect size $(f=0.25$; Howe et al., 2009) and a power of 0.80 , showed that a total sample size of 136 participants was needed. Hence, we compared the data from Experiments $1(n=72)$ and $2(n=68)$ to examine the effect of time (total $N=140)$. As no a priori 
hypotheses were formulated with regard to Remember/Know responses, results pertaining to these judgments can be found on the OSF (https://osf.io/2eayz/).

\subsection{Free Recall}

True Recall. A 2 (Condition: Eye Movements vs. Control) $\times 2$ (Valence: Negative vs. Neutral) $\times 2$ (Time: Immediate vs. Delayed) repeated measures ANOVA was performed on correct recall. The threeway interaction was non-significant, $F(1,136)=2.30, p=.13$, $\eta_{\text {partial }}^{2}=.017$. A statistically significant interaction effect between condition and time emerged, $F(1,136)=9.60, p=.002, \eta_{\text {partial }}^{2}=.066$, $\mathrm{BF}_{10}=3.21$. First, simple effect analysis revealed a statistically significant simple main effect of time for both conditions. That is, participants in the control condition in the immediate condition (Experiment $1 ; M=0.32, S D=0.10)$ recalled more hits than control participants in Experiment $2(M=0.13, S D=0.09), F(1,136)=68.36, p<.001$, $\eta_{\text {partial }}^{2}=.335$. Participants in the eye movement condition in Experiment 1 also recalled more hits $(M=0.27, S D=0.09)$ than eye movement participants in Experiment $2(M=0.19, S D=0.11), F$ $(1,136)=11.62, p=.001, \eta_{\text {partial }}^{2}=.079$. All other interactions were non-significant ( $F \mathrm{~s}<3.74$, ps $>.055)$.

False Recall. A 2 (Condition: Eye Movements vs. Control) $\times 2$ (Valence: Negative vs. Neutral) $\times 2$ (Time: Immediate vs. Delayed) repeated measures ANOVA was performed on false recall and a similar pattern was found. That is, no significant three-way interaction emerged, $F(1,136)=0.14, p=.71$. A statistically significant interaction effect between condition and time emerged, $F(1,136)=5.09$, $p=.026, \eta_{\text {partial }}^{2}=.036, \mathrm{BF}_{10}=0.09$. Simple effect analysis revealed a statistical significant simple main effect of time, but only for the control condition. Participants in the control condition of Experiment 1 $(M=0.29, S D=0.17)$ had higher false recall levels than control participants of Experiment $2(M=0.19, S D=0.14 ; F(1,136)=7.35$, $p=.008, \eta_{\text {partial }}^{2}=.512$ ). All other interactions were non-significant (Fs $<1.90, p s>.171)$.

Intrusions. A 2 (Condition: Eye Movements vs. Control) $\times 2$ (Time: Immediate vs. Delayed) ANOVA performed on uncorrected number of intrusions yielded no statistically significant interaction, $F$ $(1,136)=0.15, p=.700$. No main effect of condition was found, $F$ $(1,136)=1.57, p=.212$. A significant main effect of time was found, $F$ $(1,136)=13.09, p<.001, \eta_{\text {partial }}^{2}=.088, \mathrm{BF}_{10}=7.94$. That is, when memory was immediately tested (Experiment 1 ), fewer intrusions were recalled $(M=1.50, S D=0.28)$ than when memory was tested after a delay $(M=2.91, S D=0.29$; Experiment 2$)$.

\subsection{Recognition}

Hit Rates. A 2 (Condition: Eye Movements vs. Control) $\times 2$ (Valence: Negative vs. Neutral) $\times 2$ (Time: Immediate vs. Delayed) repeated measures ANOVA performed on hits yielded a non-significant three-way interaction, $F(1,136)=0.67, p=.41$. A statistically significant interaction effect emerged between condition and time, $F$ $(1,136)=5.14, p=.025, \eta_{\text {partial }}^{2}=.036, \mathrm{BF}_{10}=6.88$. Simple effect analysis revealed a simple main effect of time for both conditions. That is, control participants in Experiment 1 had more hits $(M=0.83$, $S D=0.09)$ than control participants in Experiment $2(M=0.64$, $\left.S D=0.16 ; F(1,136)=39.35, p<.001, \eta_{\text {partial }}^{2}=.224\right)$. Eye movement participants in Experiment 1 had more hits $(M=0.78$, $S D=0.12)$ than eye movement participants in Experiment 2 $\left(M=0.69, S D=0.13 ; F(1,136)=9.96, p<.002, \eta_{\text {partial }}^{2}=.068\right)$. The simple main effect of condition was statistically non-significant ( $p s>.13)$. All other interactions were non-significant $(F s<3.11$, ps $>.080)$.

False Recognition. A 2 (Condition: Eye Movements vs. Control) $\times 2$ (Valence: Negative vs. Neutral) $\times 2$ (Time: Immediate vs. Delayed) repeated measures ANOVA performed on false recognitions yielded no statistically significant interactions ( $F s<3.58$, ps $>.060$ ). A main effect of valence was found, $F(1,136)=12.39, p<.001$, $\eta_{\text {partial }}^{2}=.083, \mathrm{BF}_{10}=29.04$. More negative words $(M=0.75$, $S D=0.25)$ were recalled compared with neutral words $(M=0.67$, $S D=0.27$.

\section{Discussion}

The overall pattern observed in Experiment 2 was that after a delay of $48 \mathrm{~h}$, more false memories for both recall and recognition were found in the eye movement condition than in the control condition. This effect even persisted when we looked at the corrected recognition scores (see Exploratory Analyses). Interestingly, we also found that the eye movement condition had overall higher correct memory levels than the control condition, an effect that has previously been observed by Nieuwenhuis et al. (2013). In line with Shah and Knott (2018), participants who performed eye movements made more remember responses than control participants.

\section{General discussion}

EMDR aims to change the quality of autobiographical memories of patients who suffer from aversive memories. Understandably, much of the literature on EMDR has understandably focused on its positive effects (i.e., reductions in vividness and emotionality; see e.g., van den Hout, Eidhof, Verboom, Littel, \& Engelhard, 2014). However, researchers have recently begun to address unintended side effects of psychotherapy (e.g., Rozental, Kottorp, Boettcher, Andersson, \& Carlbring, 2016) and one of these are false memories. During EMDR, parts of the traumatic memory will be retrieved until the vividness and emotionality linked to the traumatic memory sufficiently declined (van den Hout \& Engelhard, 2012). However, each time a memory is retrieved, memory is reconstructed and during such reconstruction, false memories may arise (McNally, 2005). The current experiments examined whether eye movements, as used in EMDR, might enhance the production of spontaneous false memories.

The main results can be summarized as follows. First, when participants had to perform eye movements during memory retrieval immediately after the encoding of stimuli (Experiment 1), eye movements did not significantly increase correct memory or false memory rates. Second, when memory was tested after a $48 \mathrm{~h}$ delay (Experiment 2), eye movement participants had higher correct and false memory rates than control participants. In line with Nieuwenhuis et al. (2013), we found in Experiment 2 that participants who performed eye movements recalled and recognized more presented words (i.e., correct memories) than control participants. Importantly, even when we corrected for this enhanced memory effect in Experiment 2, eye movements were still associated with higher false memory levels.

Third, we found that eye movement participants (Experiment 2) recalled more correct neutral items than control participants. This is interesting, as the working memory account would lead one to predict that eye movements reduce the vividness and emotionality of both neutral and traumatic memories, and as a result, both types of memories will become less salient. However, we, and others (e.g., van den Hout et al., 2014; but see; Littel, Remijn, Tinga, Engelhard, \& van den Hout, 2017) noted that eye movements do not undermine the quality of neutral memories. This finding requires follow up research, because at face value it is difficult to reconcile with the working memory account.

Fourth, in line with Shah and Knott (2018), we found that eye movement participants made more remember responses for critical lures than control participants (Experiment 2). One distinct possibility if that performing eye movements, may make it more difficult for participants to accurately discriminate between true and false items (Mather, Henkel, \& Johnson, 1997). As a result, false items might be evaluated more often as remembered in the eye movement than in the control condition. 
One prominent framework for understanding spontaneous false memories is FTT (Brainerd \& Reyna, 2002). FTT posits that memories are sustained by two independent memory traces: verbatim (i.e., itemspecific characteristics of an experience) and gist (i.e., general meaning of the experience) traces. One of the main tenets of FTT is verbatim traces will disintegrate more rapidly than gist traces, causing individuals to rely over time more on the general meaning of events (i.e., gist traces). FTT assumes that false memories are the result of overreliance on gist traces when verbatim traces have become inaccessible. To the extent that performing eye movements make memories less salient, FTT would predict that it encourages individuals to rely on the gist of experiences, thereby promoting false memories. However, FTT also postulates than when correct memory increases, reliance on verbatim traces increases as well, thereby lowering false memory rates (Brainerd \& Reyna, 2002). Our findings are difficult to reconcile with this perspective. That is, in Experiment 2, we found that eye movements are associated with both elevated correct memory levels and increased false memories. Also, although control participants of Experiment 2 recalled and recognized fewer hits than control participants in Experiment 1 , the two control groups did not differ with regard to false recall and recognition, a pattern that runs counter to what FTT would predict.

An alternative framework is the Associative-Activation Theory (AAT; 9Howe et al., 2009), which specifies that during the encoding of an event, spreading activation will occur. This spreading activation connects the event to associated theme nodes in an individual's knowledge base (e.g., memories of going to a beach or a park are stored under the general topic of 'going out'). Because of this spreading activation, concepts might become activated that were not part of, but only related to, the encoded event. The activation of such not-experienced concept can lead to the creation of false memories. AAT predicts that an increase in correct memories goes along with an increase in false memories (Howe et al., 2009). By implication, when people retrieve more correct memories due to eye movements, more spreading activation will occur. As a result, the chance that associated, but not experienced, concepts will be activated increases and this will promote false memories. The fact that we found a significant correlation between true and false recall in Experiment $2(r(34)=0.395, p=.021)$ supports such an interpretation.

The current experiments have some important limitations. First, the DRM paradigm has been criticized for its lack of ecological validity (for an overview see Wade et al., 2007; but see Otgaar, Muris, Howe, \& Merckelbach, 2017). For example, Patihis, Frenda, and Loftus (2018) showed that there is no relationship between endorsement of lures in the DRM paradigm and autobiographical false memories. The DRM paradigm generally does not involve autobiographical memories, whereas autobiographical memories are usually the primary focus of EMDR therapists. Indeed, the results obtained with the DRM paradigm in the current experiments are only a first step to examine the susceptibility to spontaneous false memories after performing eye movements. By using virtual reality techniques (i.e., experience real life situations within a simulation setting) to create autobiographical material, future research could examine false memory proneness after performing eye movements during retrieval of autobiographical memories.

A second limitation is that we employed the EMDR kit for our eye movement manipulation. In other research (e.g., van den Hout et al., 2014), a computerized eye movement task was used and it might well be the case that this technique induces more reliable eye movements. On the other hand, the kit is used in clinical practice (https://www. emdrkit.com/) and hence, our results might be informative for what might occur during therapeutic sessions.

Third, the a priori power analysis was based on effect sizes observed in previous work on false memories (Howe et al., 2009). However, Morey and Lakens (2016) argued that basing the power of new studies on effect sizes from previous studies is not ideal, as one is indirectly selecting insufficient power for the study at hand. As the Bayes Factor depends on sample size (De Santis, 2007), the low power probability of statistical tests in the current experiments might explain the anecdotal Bayes Factors (i.e., BF $<1$ ) for the critical main effects in Experiment 1.

Some researchers observed that performing eye movements during memory recall increases individuals' susceptibility to misinformation that is offered by others, which is one prominent source of false memories (Houben et al., 2018; but see; Calvillo \& Emami, 2019; van Schie \& Leer, 2019). Our results indicate that eye movements might increase both correct memories and spontaneous false memories as well. Of course, this finding needs replication and its boundaries and generalizability need to be examined. However, given this state of affairs, EMDR therapists are well advised to take potential false memory effects of their intervention into account.

\section{Funding}

This research did not receive any specific grant from funding agencies in the public, commercial, or not-for-profit sectors.

\section{CRediT authorship contribution statement}

Sanne T.L. Houben: Conceptualization, Methodology, Formal analysis, Investigation, Resources, Writing - original draft, Visualization, Project administration. Henry Otgaar: Conceptualization, Methodology, Writing - review \& editing, Supervision. Jeffrey Roelofs: Conceptualization, Methodology, Writing - review \& editing, Supervision. Tom Smeets: Writing - review \& editing. Harald Merckelbach: Writing - review \& editing, Supervision.

\section{Declaration of competing interest}

None.

\section{Acknowledgements}

$\mathrm{SH}, \mathrm{HO}$, and JR developed the study design. SH tested the participants and performed the statistical analyses under the supervision of HO and JR. HO, JR, TS, and HM provided critical revisions. All authors approved the final version of the manuscript for submission.

\section{References}

Baddeley, A. D. (1998). Human memory: Theory and practice. Needham Heights, MA: Allyn \& Bacon.

Bernstein, E. M., \& Putnam, F. W. (1986). Development, reliability and validity of a dissociation scale. The Journal of Nervous and Mental Disease, 174, 727-735.

Bookbinder, S. H., \& Brainerd, C. J. (2016). Emotion and false memory: The contextcontent paradox. Psychological Bulletin, 142, 1315-1351. https://doi.org/10.1037/ bul0000077.

Brainerd, C. J., \& Reyna, V. F. (2002). Fuzzy-trace theory and false memory. Current Directions in Psychological Science, 11, 164-169. https://doi.org/10.1111/1467-8721. 00192.

Calvillo, D. P., \& Emami, A. S. (2019). Do lateral eye movements increase susceptibility to misinformation? A registered replication. Psychonomic Bulletin \& Review. https://doi. org/10.3758/s13423-019-01641-6.

Christman, S. D., Propper, R. E., \& Dion, A. (2004). Increased interhemispheric interaction is associated with decreased false memories in a verbal converging semantic associates paradigm. Brain and Cognition, 56, 313-319. https://doi.org/10.1016/j. bandc. 2004.08.005.

De Santis, F. (2007). Alternative Bayes factors: Sample size determination and discriminatory power assessment. Test, 16, 504-522. https://doi.org/10.1007/s11749006-0017-7.

Deese, J. (1959). On the prediction of occurrence of particular verbal intrusions in immediate recall. Journal of Experimental Psychology, 58, 17-22.

Faul, F., Erdfelder, E., Lang, A.-G., \& Buchner, A. (2007). G*Power 3: A flexible statistical power analysis program for the social, behavioural, and biomedical sciences. Behavior Research Methods, 39, 175-191. https://doi.org/10.3758/BF03193146.

Gallo, D. A. (2010). False memories and fantastic beliefs: 15 years of the DRM illusion. Memory \& Cognition, 38, 833-848. https://doi.org/10.3758/MC.38.7.833.

Gunter, R. W., \& Bodner, G. E. (2008). How eye movements affect unpleasant memories: Support for a working-memory account. Behaviour Research and Therapy, 46, 
913-931. https://doi.org/10.1016/j.brat.2008.04.006.

Houben, S. T. L., Otgaar, H., Roelofs, J., \& Merckelbach, H. (2018). Lateral eye movements increase false memory rates. Clinical Psychological Science, 6, 610-616. https:// doi.org/10.1177/2167702618757658.

van den Hout, M. A., Eidhof, M. B., Verboom, J., Littel, M., \& Engelhard, I. M. (2014). Blurring of emotional and non-emotional memories by taxing working memory during recall. Cognition \& Emotion, 28, 717-727. https://doi.org/10.1080/02699931. 2013.848785 .

van den Hout, M., \& Engelhard, I. M. (2012). How does EMDR work? Journal of Experimental Psychopathology, 3, 724-738. https://doi.org/10.5127/jep.028212.

Howe, M. L., Wimmer, M. C., Gagnon, N., \& Plumpton, S. (2009). An associative-activation theory of children's and adults' memory illusions. Journal of Memory and Language, 60, 229-251. https://doi.org/10.1016/j.jml.2008.10.002.

JASP Team (2019). JASP (version 0.11.1). ([Computer software]).

de Jongh, A., \& ten Broeke, E. (2016). Handboek EMDR: Een geprotocolleerde behandelmethode voor de gevolgen van psychotrauma [EMDR handbook: A treatment protocol for the consequences of psychotrauma]. Amsterdam, the Netherlands: Pearson.

Knott, L. M., \& Dewhurst, S. A. (2007a). Divided attention at retrieval disrupts knowing but not remembering. Memory, 15, 664-674. https://doi.org/10.1080/ 09658210701467137.

Knott, L. M., \& Dewhurst, S. A. (2007b). The effects of divided attention at study and test on false recognition: A comparison of DRM and categorized lists. Memory \& Cognition, 15, 664-674. https://doi.org/10.1080/09658210701467137.

Lee, C. W., \& Cuijpers, P. (2013). A meta-analysis of the contribution of eye movements in processing emotional memories. Journal of Behavior Therapy and Experimental Psychiatry, 44, 231-239. https://doi.org/10.1016/j.jbtep.2012.11.001.

Leer, A., Engelhard, I. M., Lenaert, B., Struyf, D., Vervliet, B., \& Hermans, D. (2017). Eye movement during recall reduces objective memory performance: An extended replication. Behaviour Research and Therapy, 92, 94-105. https://doi.org/10.1016/j. brat.2017.03.002.

Littel, M., Remijn, M., Tinga, A. M., Engelhard, I. M., \& van den Hout, M. A. (2017). Stress enhances the memory-degrading effect of eye movements on emotionally neutral memories. Clinical Psychological Science, 5, 316-324. https://doi.org/10.1177/ 2167702616687292.

Littel, M., van Schie, K., \& van den Hout, M. A. (2017). Exploring expectation effects in EMDR: Does prior treatment knowledge affect the degrading effects of eye movements on memory? European Journal of Psychotraumatology, 8(sup1), 1328954. https://doi.org/10.1080/2008198.2017.1328954.

Loftus, E. F. (2004). Memories of things unseen. Current Directions in Psychological Science, 13, 145-147. https://doi.org/10.1111/j.0963-7214.2004.00294.x.

Mather, M., Henkel, L. A., \& Johnson, M. K. (1997). Evaluating characteristics of false memories: Remember/know judgments and memory characteristics questionnaire compared. Memory \& Cognition, 25, 823-837. https://doi.org/10.3758/BF03211327.

McNally, R. J. (2005). Debunking myths about trauma and memory. Canadian Journal of Psychiatry, 50, 817-822. https://doi.org/10.1177/070674370505001302.

Morey, R. D., \& Lakens, D. (2016). Why most of psychology is statistically unfalsifiable. Found at https://github.com/richardmorey/psychology_resolution.

Moritz, S., Fieker, M., Hottenrott, B., Seeralan, T., Cludius, B., et al. (2015). No pain, no gain? Adverse effects of psychotherapy in obsessive-compulsive disorder and its relationship to treatment gains. Journal of Obsessive-Compulsive and Related Disorders, 5,
61-66.

Nieuwenhuis, S., Elzinga, B. M., Ras, P. H., Berends, F., Duijs, P., Samara, Z., et al. (2013) Bilateral saccadic eye movements and tactile stimulation, but not auditory stimulation, enhance memory retrieval. Brain and Cognition, 81, 52-56. https://doi.org/10. 1016/j.bandc.2012.10.003.

Otgaar, H., Muris, P., Howe, M. L., \& Merckelbach, H. (2017). What drives false memories in psychopathology? A case for associative activation. Clinical Psychological Science, 5, 1048-1069. https://doi.org/10.1177/2167702617724424.

Otgaar, H., Peters, M., \& Howe, M. L. (2012). Dividing attention lowers children's but increase adults' false memories. Journal of Experimental Psychology: Learning, Memory, and Cognition, 38, 204-210. https://doi.org/10.1037/a0025160.

Parker, A., \& Dagnall, N. (2007). Effects of bilateral eye movements on gist based false recognition in the DRM paradigm. Brain and Cognition, 63, 221-225. https://doi.org/ 10.1016/j.bandc.2006.08.005

Parker, A., \& Dagnall, N. (2012). Effects of saccadic bilateral eye movements on memory in children and adults: An exploratory study. Brain and Cognition, 78, 238-247. https://doi.org/10.1016/j.bandc.2012.01.007.

Patihis, L., Frenda, S. J., \& Loftus, E. F. (2018). False memory tasks do not reliably predict other false memories. Psychology of Consciousness: Theory, Research, and Practice, 5, 140-160. https://doi.org/10.1037/cns0000147.

Pesta, B. J., Murphy, M. D., \& Sanders, R. E. (2001). Are emotionally charged lures immune to false memory? Journal of Experimental Psychology: Learning, Memory, and Cognition, 27, 328-338. https://doi.org/10.1037//0278-7393.27.2.328.

Roediger, H. L., \& McDermott, K. (1995). Creating false memories: Remembering words not presented in a list. Journal of Experimental Psychology: Learning, Memory, and Cognition, 21, 803-814. https://doi.org/10.1037/0278-7393.21.4.803.

Rozental, A., Kottorp, A., Boettcher, J., Andersson, G., \& Carlbring, P. (2016). Negative effects of psychological treatments: An exploratory factor analysis of the negative effects questionnaire for monitoring and reporting adverse and unwanted events. PLoS One, 11, e0157503. https://doi.org/10.1371/journal.pone.0157503.

Shah, D., \& Knott, L. M. (2018). The role of attention at retrieval on the false recognition of negative emotional DRM lists. Memory, 26, 269-276. https://doi.org/10.1080/ 09658211.2017.1349803.

Shapiro, F. (1989). Efficacy of the eye movements desensitization procedure in the treatment of traumatic memories. Journal of Traumatic Stress, 2, 199-223. https:// doi.org/10.1002/jts.2490020207.

Shapiro, F., \& Maxfield, L. (2002). Eye movement desensitization and reprocessing (EMDR): Information processing in the treatment of trauma. Psychotherapy in Practice, 58, 933-946. https://doi.org/10.1002/jclp.10068.

Snodgrass, J. G., \& Corwin, J. (1988). Pragmatics of measuring recognition memory: Applications to dementia and amnesia. Journal of Experimental Psychology: General, 117, 34-50. https://doi.org/10.1037/0096-3445.117.1.34.

Tulving, E. (1985). Memory and consciousness. Canadian Psychology, 26, 1-12.

van Schie, K., \& Leer, A. (2019). Lateral eye movements do not increase false-memory rates: A failed direct-replication study. Clinical Psychological Science, 7(5), 1159-1167. https://doi.org/10.1177/2167702619859335.

Wade, K. A., Sharman, S. J., Garry, M., Memon, A., Mazzoni, G., Merckelbach, H., et al. (2007). False claims about false memory research. Consciousness and Cognition, 16, 18-28. https://doi.org/10.1016/j.concog.2006.07.001. 